\title{
R. S. BALL'S MECHANICS: BRINGING NEWTON TO THE MASSES?
}

\author{
CHRISTOPHER D. HOLLINGS
}

In 1879, the Irish astronomer Robert Stawell Ball published a slim book entitled simply Mechanics [1]. This book appeared as part of the series of 'London Science Class-Books', published by Longmans, Green \& Co. These books were intended as elementary science texts for use in schools, and, as a consequence, their mathematical content was quite basic - even for those books on supposedly mathematical topics. In this article, I will look at Ball's handling of his subject, and compare his book to its distant ancestor: Newton's Principia.

\section{The London Science Class-Books}

The creators and editors of the 'London Science Class-Book' series, which was launched in the 1870s, were G. Carey Foster (1835-1919) and Sir Philip Magnus (1842-1933). The former was both a physicist and a chemist, and had been Professor of Physics at UCL since 1865 [2]. Magnus, on the other hand, was a politician and educational reformer, who would later be instrumental in the creation of the City and Guilds Institute $[3,4]$. Their motivation in creating this series of texts was stated quite clearly in the editorial preface that appeared at the beginning of each volume:

Notwithstanding the large number of scientific works which have been published within the last few years, it is very generally acknowledged by those who are practically engaged in Education, whether as Teachers or as Examiners, that there is still a want of Books adapted for school purposes upon several important branches of Science. The present SERIES will aim at supplying this deficiency. $[1, \mathrm{p} . \mathrm{v}]$

Foster and Magnus went on to outline their further specifications for the series: that the books would be "composed with special reference to their use in schoolteaching", that they would be "trustworthy and accurate", and, moreover, that

... although the treatment of each subject will be strictly elementary, the fundamental facts will be stated and discussed with the

Date: October 27, 2016.

This article is based on a talk entitled 'R. S. Ball's Mechanics and the 'London Science Class-Books', or bringing Newton to the masses?' delivered in the section on 'Mathematics and Society' at the British Applied Mathematics Colloquium, Oxford, 5-8 April 2016. Thanks must go to Mark McCartney for his comments on an early draft. 

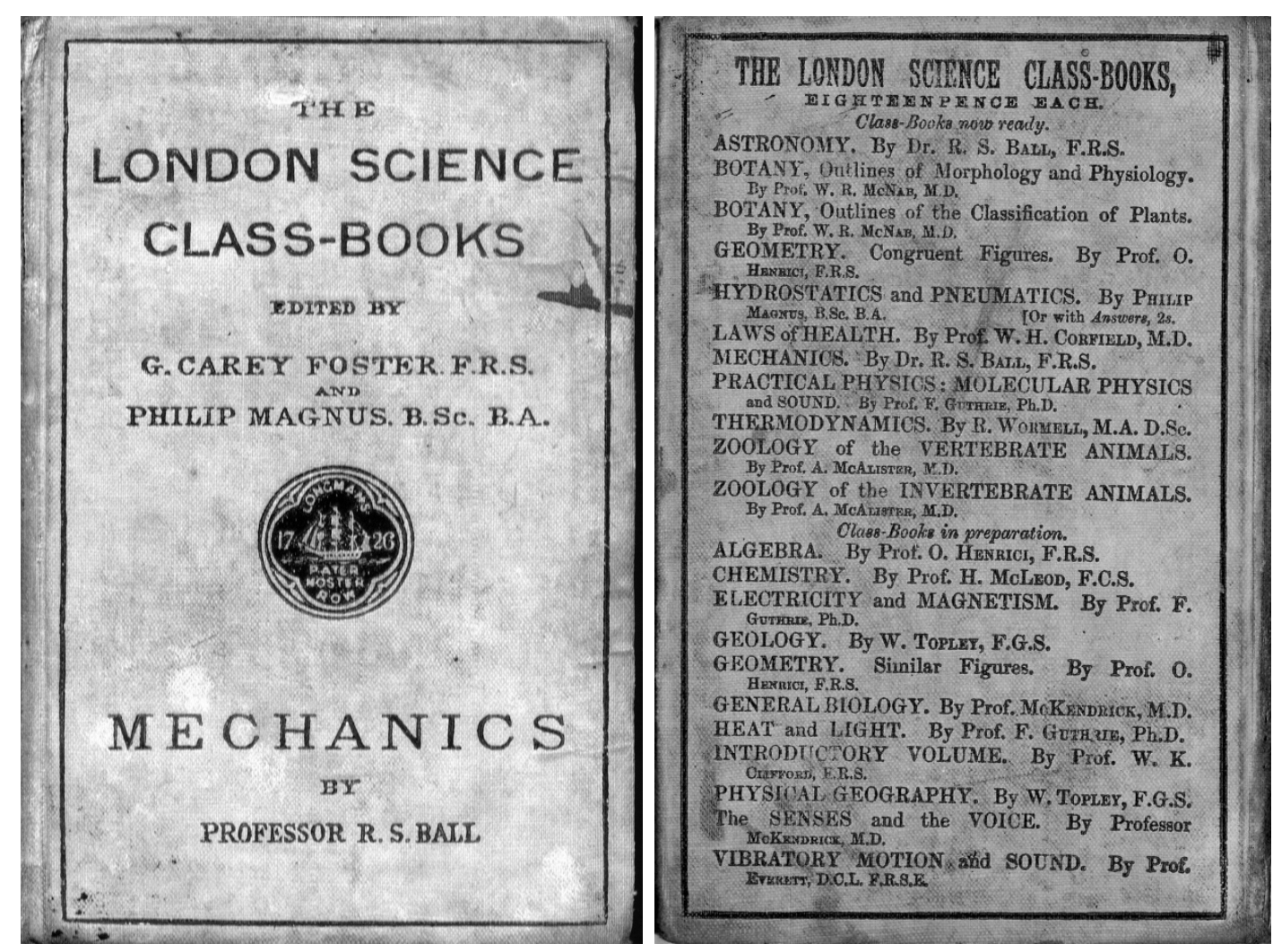

FiguRE 1. Front and back covers of Ball's Mechanics

fulness needed to place their scientific significance in a clear light ... [1, p. vi $]$

Their hope was that "eventually each of the chief branches of Science shall be represented by one or more volumes". Indeed, books were proposed on subjects ranging from astronomy to zoology (see Figure 1).

Another of Foster and Magnus' stated goals was the enlistment as authors of "men who combine special knowledge of the subjects on which they write with practical experience in Teaching" [1, p. vi]. Their prospective authors ${ }^{1}$ included professors at various universities and institutions; amongst these, Ball certainly fit the bill as a man with "special knowledge" and "practical experience in Teaching".

\section{Sir Robert StaWell Ball}

Ball was born in Dublin in $1840,{ }^{2}$ and much of his career was spent in and around that city. Following study at Trinity College, Dublin, he took a job as

\footnotetext{
${ }^{1}$ I refer here to 'proposed books' and 'prospective authors' because only a few of the books listed as 'in preparation' on the back cover of [1] actually appeared in print; the London Science Class-Books appear to have floundered as a series - more research is needed to determine why.

${ }^{2}$ The details given here are drawn largely from [5].
} 


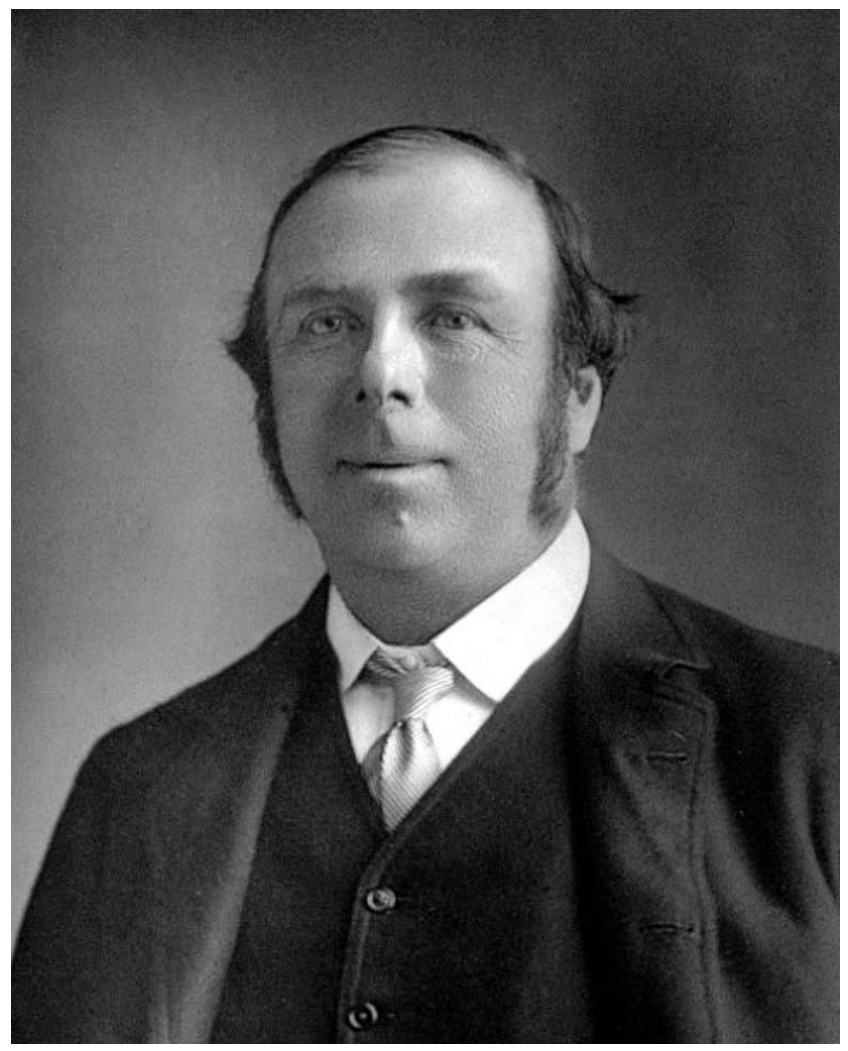

Figure 2. Sir Robert Stawell Ball (1840-1913). Photograph by W. \& D. Downey. [Credit: Wellcome Library, London]

tutor to the children of the Earl of Rosse at Birr Castle in County Offaly, where he was able to operate the giant telescopes built there by the earl. Two years later, off the back of this experience, Ball was appointed Professor of Applied Mathematics and Mechanics at the new Royal College of Science in Dublin, where he remained until his successful application for the posts of Royal Astronomer for Ireland and Andrews Professor of Astronomy at the University of Dublin in 1874. As Royal Astronomer, Ball's place of work was the Dunsink Observatory outside Dublin, which had for many years been the home of William Rowan Hamilton when he had held the post; it seems appropriate therefore that Ball would in later years be president of the short-lived Quaternion Society. In 1892, he took up the Lowndean Professorship of Astronomy and Geometry in Cambridge, and remained in this position until his death in 1913.

Besides his work as an astronomer, Ball's academic claim to fame was his development of screw theory - the mathematical theory of pairs of vectors, with a view to applications in the mechanics of rigid bodies - which he laid out in two monographs $[6,7]$. He was also the author of educational materials - his Experimental Mechanics of 1871 [8] was written in the same practical style that he 
later used for Mechanics - and was an active populariser of science (astronomy in particular), writing several articles, as well as delivering the Royal Institution Christmas Lectures, on a range of astronomical subjects, on no less than five occasions $(1881,1887,1892,1898,1900)$. In connection with his educational interests, he was president of the Mathematical Association in 1900.

\section{MECHANICS}

As one would perhaps expect, given its target readership, Ball's Mechanics is a very straightforward book; it is quite practical in its approach to the subject, and contains many examples of mechanics at work in day-to-day applications, such as in levers, pulleys, and similar such devices. These applications are illustrated beautifully with pictures that Ball derived (with credit) from an earlier text on Mechanics: Charles Delaunay's Cours élémentaire de mécanique théorique et appliquée, originally published in 1851 (see, for example, Figure 3).

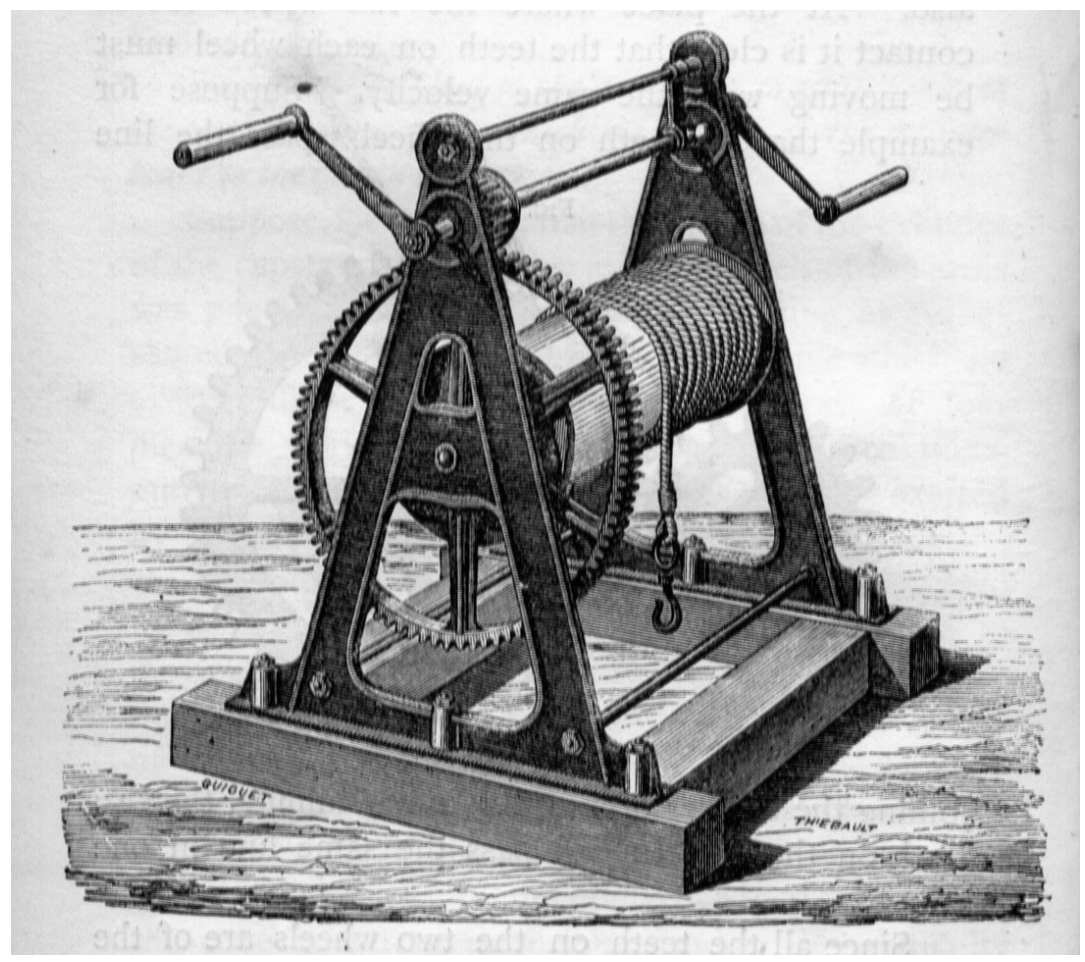

Figure 3. Illustration of a weight-lifting machine from Mechanics, p. 114

Ball's book is written in an engaging and very down-to-earth style. Take, for example, the following, which appears as part of his discussion of inertia:

A man is riding on horseback, and the horse stops suddenly. If the horse has previously been going rapidly his rider is in great danger of being thrown over the horse's head. Why is this? [1, p. 16] 
Another nice example appears later on, during a treatment of friction:

A sleigh is a very admirable vehicle on a smooth surface ... [1, p. 98]

Ball then went on to extol the virtues of the wheel! The invocation of horses, sleighs, etc., was not simply a matter of literary flourish, however, but an integral part of the practical nature of the book: such comments are often the introduction to a thought experiment that illustrates the material under consideration.

A glance at the table of contents of Ball's book (Table 1) reveals that it was indeed quite elementary; the fact that ten chapters intervene between Ball's treatments of Newton's first and second laws of motion perhaps gives an indication of the level. Basic notions appear in the early chapters, all reinforced by reference to practical devices, ranging from projectiles to safety valves.

I. Preliminary notions on movement

II. Preliminary notions on force

III. The principle of the lever

IV. Equilibrium of parallel forces

V. The parallelogram of force

VI. Gravitation

VII. Illustrations of the equilibrium of forces

VIII. The inclined plane

IX. Friction

X. Energy

XI. Practical illustrations of mechanical principles

XII. The motion of a falling body

XIII. The second law of motion

XIV. The third law of motion

TABLE 1. Table of contents of Ball's Mechanics

Much of the mathematics of the book is presented verbally, with a little arithmetic, supplemented here and there by the language of ratios, as well as some Euclidean geometry; no calculus is used. Moreover, the use of algebra is rather limited; none appears until p. 134 (of 167), where Ball commented:

The use of algebraical symbols will enable the results at which we

have arrived to be expressed very concisely.

He then went on to employ an algebraic notation for the first two of the familiar equations for the motion of falling bodies under uniform gravitational acceleration $g$ :

$$
v=g t, \quad s=\frac{1}{2} g t^{2},
$$

where $s$ is displacement, $v$ is final velocity, and $t$ is time. However, when it came to extending these to the more general situation of non-zero initial velocity $u$, 
where we might expect to see such expressions as $v=u+g t$ or $s=u t+\frac{1}{2} g t^{2}$, Ball reverted to a verbal presentation.

Thus, we gain a sense of the level of student for which Ball was writing: one who had learnt no calculus, and for whom even a little basic algebra was to be largely avoided. Nevertheless, something a little more interesting does appear from time to time, such as the following example, illustrated by Figure 4, of the determination of the centre of gravity of a given shape, just one of several problems of this type to be found in Ball's text:

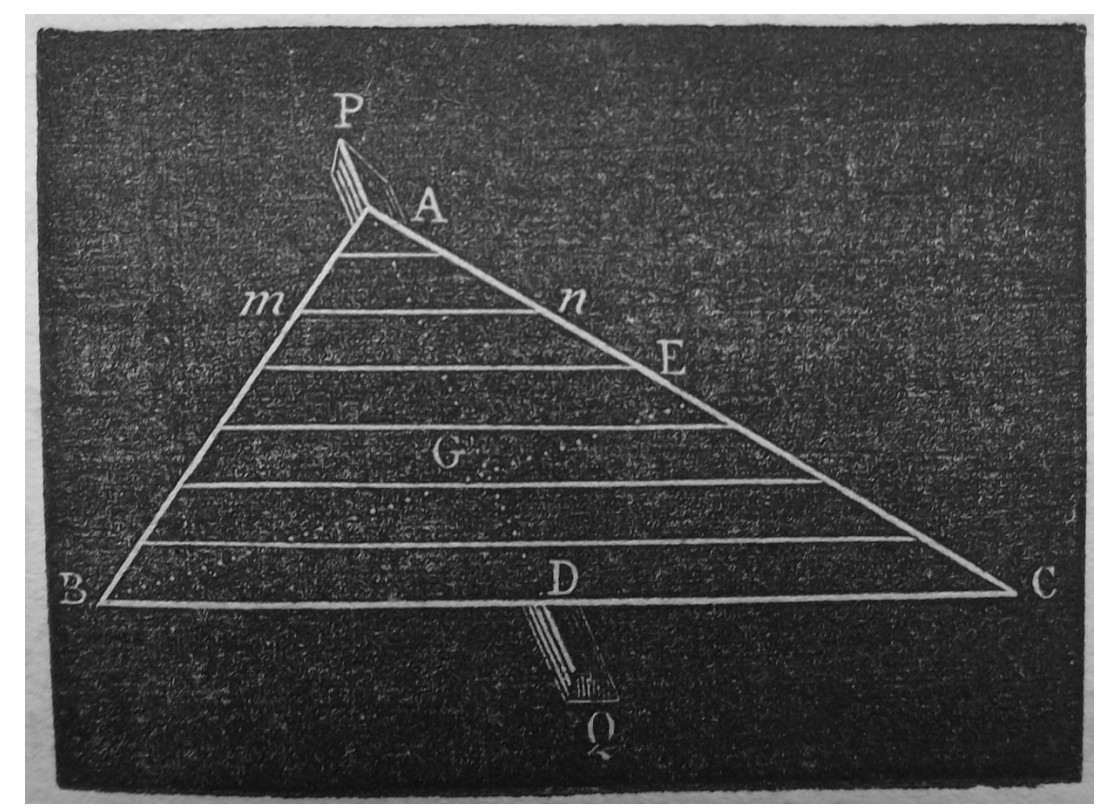

Figure 4. Illustration of a problem on centre of gravity from $\mathrm{Me}$ chanics, p. 64

1. Find the centre of gravity of the triangular plate $A B C \ldots$

Bisect the base $B C$ of the triangle in the point $D$, then it can easily be proved that a line $A D$, drawn from the vertex of the triangle to the point of bisection of the base would bisect every line parallel to the base, such as $m n$. Let a large number of lines be drawn parallel to the base, and suppose that the triangle is placed so that $A D$ lies along the edge of a prism $P Q$. If the strips into which the triangle is divided by these lines are so excessively narrow that we may regard them merely as slender rods, it is evident that each of the strips would balance itself separately on the edge of the prism, because the middle point of the strip is over the edge of the prism. As each of the strips would balance by itself, it is plain that the whole triangle which is formed of these strips 
will balance, and, therefore, the centre of gravity of the triangle must lie on the line $A D$.

In the same way it can be shown that the centre of gravity must lie in the line $B E$, which is drawn from the vertex $B$ to bisect the side $A C$. The centre of gravity must, therefore, lie at the point of intersection of these two bisectors, i.e. at the point $G$. [1, p. 64-65]

Note the phrase "the strips into which the triangle is divided by these lines are so excessively narrow that we may regard them merely as slender rods" - Ball appears to have taken the pragmatic physicist's approach to the foundational issues that are implicit here, avoiding any mention of infinitesimals, and thus sidestepping the need for justification and philosophical discussion.

\section{NEWTON}

Thus, Ball's Mechanics was an elementary book with a practical bias. The mathematics that it contains is not deep; indeed it treats mechanics more as a branch of physics than of mathematics. However, there are certain features of the book that invite a comparison with Newton's Principia [9]. ${ }^{3}$

In some respects, this is a rather fatuous comparison to make: the Principia is far from elementary, and certainly does not avoid mathematics in the way that Mechanics does. With regard to the mathematics that Ball does employ, we see certain superficial similarities of technique between Ball and Newton: geometry and ratio, plus the cutting of areas into narrow strips - but Newton of course had no qualms about using infinitesimals!

That there should be some overlap in subject matter is hardly surprising, since modern mechanics essentially derives from Newton: for example, Ball has the parallelogram of forces as the subject of his Chapter V, whilst the same topic appears in the Principia as the first corollary to the laws of motion. However, this is not the full extent of the comparison that I wish to draw; I want also to look at their styles. A fact that is seldom remarked upon is that Newton's Principia can perhaps be viewed as two complementary interleaved texts: the well-known and notoriously difficult technical material, and the much more down-to-earth and discursive passages that offer extra explanation and motivation, particularly of definitions. Take, for example, the following, inserted to aid the reader's understanding of centripetal force:

A stone, whirled about in a sling, endeavours to recede from the hand that turns it ... That force ... by which the sling perpetually draws back the stone towards the hand, and retains it in its orbit ... I call the centripetal force. $[9$, p. 10$]$

Or this on the effects of the most noticeable centripetal force:

\footnotetext{
${ }^{3}$ The quotations and references here are taken from the Motte translation of the Principia.
} 
... the force of gravity is greater in valleys, less on tops of exceeding high mountains ...

A lengthy passage on the distinction between absolute and relative motion draws heavily upon the example of bodies within the hold of a ship:

... if the earth is really at rest, the body, which relatively rests in the ship, will really and absolutely move with the same velocity which the ship has on the earth. [9, p. 14]

But, on the other hand, if the Earth moves in space, the ship moves on the Earth, and the body moves within the ship, then "from these relative motions will arise the relative motion of the body on the earth" [9, p. 14].

The laws of motion appear to lend themselves particularly well to this type of additional explanation; for example, in connection with the first law, we have:

A top ... does not cease its rotation, otherwise than as it is retarded by the air. $[9$, p. 19]

And for the third:

If you press a stone with your finger, the finger is also pressed by the stone. If a horse draws a stone tied to a rope, the horse (if I may so say) will be equally drawn back towards the stone ... [9, p. 19]

All of these comments are reminiscent of Ball's use of day-to-day situations to illustrate the points in his text. Moreover, like Ball, Newton frequently described experiments, although, unlike Ball, these were no mere thought experiments, but ones that Newton had almost certainly performed - even if he occasionally mislaid his notes:

This experiment is related by memory, the paper being lost in which I had described it; so that I have been obliged to omit some fractional parts, which are slipt out of my memory; and I have no leisure to try it again. [9, p. 258]

\section{Conclusions}

So what is the point of this brief study? We have seen that Ball's Mechanics and Newton's Principia have not only a coincidence in content (not surprising), but also a coincidence in style (more surprising?). Two hundred years after it was first written, Ball had brought Newton's notoriously difficult book to what is arguably the most elementary level possible, and thus to the widest possible readership. He did this without ever invoking the name 'Newton'. ${ }^{4}$ Science that had once been beyond the appreciation of most people was now, in a suitably digested form, rather more commonplace.

\footnotetext{
${ }^{4}$ Even in Ball's longer Experimental Mechanics [8], Newton appears only once, on p. 293.
} 
There is also a lesson here to historians of mathematics who (mea culpa) teach the subject and present the Principia as representing the great 'mathematisation' of nature and the driver of a fundamental change in the interaction between mathematics and other sciences. Indeed, on some level it certainly was. And yet in Ball's text, 200 years later, we find an older, more intuitive, non-mathematical conception of mechanics still being taught and employed. We might therefore conclude - and this is perhaps a curious message with which to end an article in a mathematical journal! — that mathematisation is not the be-all and end-all.

\section{REFERENCES}

[1] Robert Stawell Ball, Mechanics, Longmans, Green \& Co., London, 1879.

[2] Graeme J. N. Gooday and Colin A. Hempstead, Foster, George Carey (18351919), Oxford Dictionary of National Biography, Oxford University Press, 2004 [http://www.oxforddnb.com/view/article/39488, accessed 26 Aug 2016]

[3] Bill Bailey, Magnus, Sir Philip, first baronet (1842-1933), Oxford Dictionary of National Biography, Oxford University Press, 2004 [http://www.oxforddnb.com/view/article/40870, accessed 26 Aug 2016]

[4] F. E. Foden, Sir Philip Magnus and the City and Guilds of London Institute, The Vocational Aspect of Education 14(29) (1962), 102-116.

[5] P. A. Wayman, Ball, Sir Robert Stawell (1840-1913), Oxford Dictionary of National Biography, Oxford University Press, 2004 [http://www.oxforddnb.com/view/article/30566, accessed 31 Aug 2016]

[6] R. S. Ball, The theory of screws: a study in the dynamics of a rigid body, Hodges, Foster, and Co., Dublin, 1876.

[7] R. S. Ball, A treatise on the theory of screws, Cambridge University Press, 1900.

[8] R. S. Ball, Experimental mechanics: a course of lectures delivered at the Royal College of Science for Ireland, Macmillan, London, 1871.

[9] Isaac Newton, Philosophice Naturalis Principia Mathematica, London, 1687; English translation by Andrew Motte, 1729; Motte's translation reprinted by Prometheus Books, New York, 1995.

Mathematical Institute, University of Oxford, Andrew Wiles Building, RadCliffe Observatory Quarter, Woodstock Road, Oxford, OX2 6GG, United KingDOM

The Queen's College, Oxford, OX1 4AW, United Kingdom

E-mail address: christopher.hollings@maths.ox.ac.uk 